\title{
PENGEMBANGAN MODEL PEMANASAN BERBASIS PERMAINAN PRAMUKA PADA SISWA SMP
}

\author{
MAHARANI FATIMA GANDASARI \\ Program Studi Pendidikan Jasmani Kesehatan dan Rekreasi \\ STKIP Pamane Talino \\ maharani.fg8@gmail.com
}

\begin{abstract}
Abstrak
Penelitian ini merupakan penelitian R\&D (Research and Development).Peneliti menggunakan model model Borg \& Gall pada penelitian ini, dimana ada 2 tahapan yakni sebagai berikut: (1) tahap pra-pengembangan, dimana kajian literature, penelitian relevan dan studi lapangan yang menjadi bagian pada tahap pra-pengembangan., (2) tahap pengembangan, dimana pada tahap ini berisi tentang penyusunan draf, validasi ahli, uji coba model skala kecil, uji coba model skala besar, dan produk akhir. Pada Uji coba skala kecil dilakukan kepada 30siswa di SMPN1 Ngabang.Sedangkan uji coba skala besar dilakukan kepada 130 siswa dari SMPN 2 Ngabang, SMP Maniamas, MtsN Ngabang, Kabupaten Landak Kalimantan Barat.Peneliti menggunakan metode Research and Developmentyaitu pengembangan pemanasan yang berupa permainan pramuka.Penggunaan teknik dalam upaya mengumpulkan data yaitu dengan menggunakan pedoman observasi serta kuesioner.Teknik analisis data yang digunakan yaitu statistik deskriptif yang kemudian di konversikan ke dalam data kualitatif.Siswa Sekolah Menegah Pertama(SMP) di Kabupaten Landak menjadi subyek penelitiannya. Penelitian ini menghasilkan secara keseluruhan dari uji skala kecil dan uji skala luas yang dilakukan peneliti (1) ketertarikan pada produk yang dihasilkan oleh peserta didik dengan rata-rata sebesar 85,59 dengan kategori "Baik", (2) produk yang diterima oleh guru pendidikan jasmani dengan rata-rata sebesar"85,55"dengan kategori "Baik", (3) pelaksanaan dari model permainan pramuka sebesar82,75 dengan kategori "Baik". (4)produk model permainan pemanasan yang diterima dengan rata-rata sebesar 85,57 dengan kategori "Baik" serta (5)pelaksanaan model permainan pramuka dengan rata-rata sebesar 82,81 dengan kategori "Baik". Simpulan pada penelitian ini yaknibahwa modelpemanasan yang berbasis permainan pramuka yang dapat diterima dengan "Baik" serta model pemanasan ini juga dapat terlaksana juga dengan "Baik".Saran yang ingin disampaikan peneliti yakni bagi guru penjaskes model pemanasan berupa permainan ini bisa menjadi alternative lain dalam pelaksanaan pembelajaran penjasakes, dan bisa juga digunakan sebagai acuan atau pedoman bagi guru penjaskes untuk dapat mengembangkan berbagai bentuk pemanasan yang lebih kreatif dan inovatif.
\end{abstract}

\author{
Kata kunci : Model, Pemanasan, Permainan Pramuka
}

\section{DEVELOPMENT OF HEATING MODEL BASED ON SCOUT GAMES ON JUNIOR HIGH SCHOOLSTUDENTS}

\begin{abstract}
This research is an $R \& D$ research (Research and Development). This research and development uses the Borg \& Gall model by simplifying it into 2 stages as follows (1) pre-development stage, this stage includes (a) literature review and relevant research and (b) field study, (2) development stage, this stage include (a) drafting, (b) expert
\end{abstract}


validation, (c) small-scale model trials, (d) large-scale model trials, and (e) final products. A small-scale trial was conducted on 30 students at SMPN 1 Ngabang. A largescale trial was conducted on 130 students from SMP Negeri 2 Ngabang, SMP Maniamas, MtsN Ngabang, Landak Regency, West Kalimantan. The method used in this research is Research and Development, namely the development of heating in the form of a scout game. Data collection techniques using observation guidelines and questionnaires with data analysis techniques using descriptive statistics and then converted to qualitative data. The research subjects were students of the First Middle School in Landak Regency. The overall results of the limited scale test and the wide scale test of product interest from students averaged 85.59 (Good), product acceptance from the teacher averaged 85.55 (Good), the feasibility of scouting games 82.75 (Good). Acceptance of the product produced an average value of 85.57 (Good) and an average game performance of 82.81 (Good). The conclusion obtained in this study is that the scout game based heating model developed can be well received and can be implemented well. It is recommended for the physical education teacher to be able to use a warm-up model in the form of a game that is produced as an illustration and reference for the physical education teacher to develop various forms of warming that are more varied and innovative.

Keywords: Model, Warming, Scouting Game

\section{PENDAHULUAN}

Bermain dapat mengontrol motorik kasar menurut Diana Mutia (2010:151) dalam hal ini anak-anak dapat mempraktikan seluruh gerakan motorik kasar contoh dengan berlari, melompat, meloncat serta gerakan lainnya, gerak tersebut tidak serta merta sekedar gerakan saja tetapi gerakan tersebut memiliki tujuan. Walaupun dalam ranah bermain gerakan yang dilakukan secara sistematis tidak terlihat beraturan akantetapi gerakan tersebut penuh arti dan tercapainya yang diinginkan yang diinginkan tercapai yakni gerakan motorik dapat berfungsi. Secara tidak sadar anak-anak terdorong untuk melakukan gerakan berjalan, meloncat, dan berputar, serta beralih gerakan setelah merespon dari irama atau instruksi yang mereka dengar.Dalam hal ini guru harus bisa menerapkan dan mengembangkan gerak siswa dalam pembelajaran, sehingga guru pun dituntut harus bisa berpartisipasi secara aktif, kreatif, inovatif dan juga menyenangkan.Sehingga metode bermain merupakan salah satu metode pembelajaranyang dilakukan dengan menerapkanbeberapa gerakan fisik/jasmani anak dalam rangka pengembangan otot secara menyeluruh.

Bermain merupakan sebuah kegiatan yang wajib dan harus dilakukan oleh anak-anak untuk bisa mengenal bagaimana lingkungan mereka disekitar, banyak juga orang dewasayang melakukan kegiatan bermain dengan tujuan menghilangkan stres.Bermain juga merupakan kegiatan yang dilakukan untuk menimbulkan kesenangan, dengan tidak memikirkan hasil akhir.Menurut Suharjana (2011, p. 4) menunjukkan bahwa bermain menjadi suatukewajiban dan kebutuhan bagi anak.Dunia bermain merupakan suatu bentuk latihan yang dilakukan supaya menemukan dan mendapatkan bakat/potensi yang ada pada anak tersebut. 
Dalam kehidupan bermain anak diberikan kesempatan untuk memperoleh pengalaman belajar yang menyenangkan. Menurut Mutohir (Sridadi, 2009, p. 47) Aktivitas bermain memiliki keuntungan yakni (a) Energi dapat terbuang, (b) memaksimalkan pertumbuhan pada keseluruhanbagian tubuh yakni tulang, otot, serta organ-organ yang ada didalam tubuh, (c) peningkatan padanafsu makan anak, (d) kemampuan anak untukterus belajar dalam mengontrol dirinya sendiri, (e) meningkatkan dan mengembangkan ketrampilan anak supaya dapat dimanfaatkan secara kontinyu, (f) kreatifitas anak dapat terus meningkatkan, (g) anak mendapatkan kesempatan untuk dapat bersosialisasi dengan yang lain, (j) anak memiliki kesempatan untuk merasakan kemenangan dan kekalahan dalam permainan, (k) anak akan belajar untuk mengikuti dan menaati peraturan, dan (l) kemampuan intelektual anak akan dapat meningkat. Sehingga pada saat bermain anak-anak akan berperilaku diatas usia rata-ratanya, diatas perilaku mereka sehari-hari, dan menganggap dirinya lebih dari yang mereka pikirkan. Adanya ciri-ciri khas bermain yaitu: (1) anak merasa senang dan gembira; (2) anak tidak merasa dipaksa untuk melakukan bermain namun hal itu akan muncul dengan sendirinya; (3) bersifat spontan dan sukarela dalam melakukan kegiatan bermain; (4) Secara bersama-sama anak akan ikut serta sesuai perang mereka masing-masing, (5) tidak bersungguh-sungguh dalam melakukan atau memerankan sesuatu; (6) menentukan dan mematuhi aturan main yang ditentukan oleh mereka sendiri; (7) Anak bersikap aktif; (8) fleksibel dalam bermain.

Menurut (Musfiroh, 2008, p.12). Berdasarkan uraian diatas, dapat disimpulkan bahwasanya bermain merupakan sebuah bentuk kegiatan yang manajika dilakukan akan menimbulkan kesenangan, kegembiraan, dan kebahagiaan, sertamelakukan aktivitas jasmani secara spontan.Selain itu kejenuhan dan stress yang dialami pada umumnya akan sedikit berkurang dengan mengikuti kegiatan bermain.

Peningkatan tumbuh kembang anak menjadi salah satu factor pada adanya berbagai macam permainan yang dimainkan oleh anak.Permainan Pramuka merupakansuatu kegiatan yang memiliki tujuan untuk menyegarkan kembali pikiran baik secara indivu maupu kelompok.Pembagian kelompok yang digunakan dalam permainan dapat ditentukan berdasarkan jumlahnya dan dapat diberi nama yang berbeda-beda antar kelompok. Kelompok yang sudah ditentukan dalam permainan tersebutakan dilakukan kompetisi dan diketahui siapa pemenang. Adanya makna dalam sebuah permainan dan nilai-nilai yang terkandung didalam permainan semuanya memiliki pesan moral yang bisa dipetik dan diterapkan dalam karakter anakserta gerak yang dapat mengandung unsur materi dalam materi pembelajaran penjas.

Permainan pramuka harus dirancang semenarik mungkin agar anak mau aktif dan tertarik untuk memainkannya, serta diharapkan dalam permainan tersebut juga harus bersifat edukasi 
sehingga tidak anak tidak hanya sekedar melakukan permainan tetapi mereka juga belajar.Permainan pramuka ini cocok untuk diterapkan pada anak usia (11-15 tahun). Permainan yang dilakukanberkaitan dengan fisik yakni, jalan, lompat dan lari.Ada beberapa orang yang berpendapat bahwa permainan pramuka merupakan permainan yang sangat membosankan, tetapi kenyataannya permainan pramuka bisa menjadi suatu permainan edukasi bagi anak.Jenis dan manfaat yang ada dalam permainan pramuka sangat beragam bisa dimainkan didalam ruangan dan diluar ruangan. Manfaat yang dapat diperolehdalam permainan pramuka cukup lengkap mulai dari pendidikan formal sekolah hingga pendidikan nonformal luar sekolah yang jumlahnya sangat tidak terbatas.

\section{METODE}

Penelitian yang dilakukan ini merupakan penelitian pengembangan (research \& development).Penelitian research \& developmentmenurut Sugiyono (2010, p. 407) merupakan penelitian yang menggunakan metode yang mana menghasilkan suatu produk dan menguji keefektifan suatu produk.Tahapan modifikasi pada penelitian ini memiliki 2 tahap yakni (1) tahap pra-pengembangan: pada tahap ini diambil atau berdasar pada permasalahan yang timbul dan ditemukan dalam setiap pembelajaran penjaskes di tingkatSekolah Menengah Pertama (SMP). Pengidentifikasianmasalah yang ada fan terkait dengan proses pembelajaran yang dilakukan oleh guru, kemudian pada tahap ini dilakukan kajian literature dan kajian penelitian yang relevan serta studi lapangan. Hasil yang didapat dari tahap pra-pengembangan nantinya akandijadikan dasar dalam melakukan Pengembangan model pembelajaran menggunakan permainan yang sederhana dalam hal ini menggunakan permainan pramuka pada kegiatan pemanasan untuk siswa SMP. Kemudian peneliti akan melakukan analisis untuk dapat mengembangkan model permainan yang nantinya sesuai dengan kebutuhan yang ada di sekolah menegah pertama Kabupaten Landak.

Langkah-langkah Pada Tahap pengembangan yakni diantaranya (a) menyusun draft model permainan yang bisa digunakan pada kegiatan pemanasan dan disesuaikan dengan materi yang akan disampaiakan, (b) validasi yang dilakukan oleh ahli, (c) uji coba kelompok kecil, (4) uji coba kelompok besar, serta (e) produk operasional terbatas. Subjek yang digunakan pada uji coba adalah sasaran yang nantinya akan memakai produk, yaitu siswa Sekolah Menengah Pertama (SMP) Kabupaten Landak. Siswa SMP yang dipilih menjadi subyek uji coba yang tertera sebagai berikut: SMPN 1 Ngabang untuk uji coba kelompok kecil, 3 SMP untuk uji coba kelompok besar diantaranya SMPN 2 Ngabang, SMP Maniamas dan Mts Ngabang.

Data kualitatif dan data kuantitatif yang dikonversi kedata kualitatif yang peneliti dapatkan dan menjadi data awal peneliti.Hasil observasi akan diperoleh data kualitatif sedangkan wawancara menghasilkan data kuantitatif diperoleh dari angket/kuesioner. Maksud kedua data tersebut 
tujuannya untuk mengetahui kualitas dari komponen-komponen pengembangan permainan pramuka yang akan dapat digunakan dalam kegiatan pemanasan.

Instrumen yang digunakan dalam penilaian ini yaitu: 1) Kuesioner untuk ahli permainan, 2) Kuesioner untuk guru dan siswauntuk mengevaluasi sejauh mana mereka tertarik terhadap permainan ini dan menerima produk permainan yang dikembangkan. Data yang peneliti peroleh kemudian dianalisis dengan menggunakan statistik deskriptif kualitatif.Analisis ini bertujuan untuk menggambarkan karakteristik data pada aspek pemanasan atau kegiatan permainan yang digunakan. Tujuan yang diinginkanmemberikan kemudahan dalam memahami data untuk proses analisis selanjutnya. Penggunaan hasil analisis datamenjadi dasar untuk merevisi/memperbaiki produk permainan yang dikembangkan. Hasil yang didapat peneliti melalui angket penilaian dan wawancara yang berupa data kuantitatif dianalisis dengan menggunakan statistik deskriptif dan kemudian data tersebut akandikonversikan ke data kualitatif

\section{HASIL DAN PEMBAHASAN}

Berdasarkan hasil yang diperoleh dari uji kelompok kecil sampai uji kelompok besar telah dilakukan dimulai dari hasil penilaian validator, hasil yang diperoleh dari uji kelompok kecil dan uji kelompok besar menunjukan bahwa produk yang dikembangkan layak untuk dapat diterapkan dalam kegiatan pemanasan penjaskes di Sekolah Menegah Pertama (SMP) dan juga produk ini bisa dikembangkan lagi oleh guru penjaskes. Analisi hasil penelitian didapatkan kesimpulan yakni sebagai berikut :

Tabel 1 Rekapitulasi Hasil Penelitian

\begin{tabular}{|c|l|c|c|}
\hline No & \multicolumn{1}{|c|}{ Jenis Data } & Rata-rata Nilai & Kategori \\
\hline 1 & Validasi & 88,87 & $\mathrm{~B}$ \\
\hline \multirow{3}{*}{2} & Keterterimaan peserta didik & & \\
\cline { 2 - 4 } & - Uji kelompok kecil & 75,8 & $\mathrm{~B}$ \\
\cline { 2 - 4 } & - Uji kelompok besar & 95,2 & $\mathrm{~A}$ \\
\hline \multirow{3}{*}{3} & Keterterimaan guru & 78,91 & $\mathrm{~B}$ \\
\cline { 2 - 4 } & - Uji kelompok kecil & 92,19 & $\mathrm{~A}$ \\
\cline { 2 - 4 } & - Uji kelompok besar & 342,10 & \\
\hline \multirow{2}{*}{} & Jumlah & 85,53 & $\mathrm{~B}$ \\
\hline & Rerata & \multicolumn{2}{|c|}{ BAIK } \\
\hline & Kesimpulan & \multicolumn{2}{|c|}{} \\
\hline
\end{tabular}

Hasil akhir yang diperoleh dari masing-masing instrumen yang dikembangkan dalam penelitian ini diperoleh nilai rata-rata 85,53 masuk ke dalam kategori BAIK, sehingga produk pengembangan model permainan dilakukan peneliti dinyatakan layak untuk dapat diterapkan /digunakan dalam kegiatan pemanasan penjaskes di tingkat Sekolah Menengah Pertama (SMP).

Peserta didik dalam melakukan pemanasan sangat antusias, senang dan dapat mengeksplor kemampuan gerak, serta dapat bergerak bebas dalam pembelajaran penjaskes, seperti yang ada 
dalam produk pengembangan yang dikembangkan. Dengan demikian produk pengembangan dari pemanasan yang dihasilkan membuat pembelajaran menjadi lebih menarik, menyenangkan, kontekstual dan menunjang materi pembelajaran yang akan diberikan. Dengan demikian produk pengembangan dari pembelajaran penjaskes yang dihasilkan membuat pembelajaran menjadi lebih menarik, menyenangkan, kontekstual dan menunjang materi penjas yang akan disampaiakn oleh guru.

Pelaksanaan uji coba berjalan dengan lancar dan menarik karena banyak siswa yang aktif dalam mengikuti pemanasan permainan pramuka.Selain kuesioner yang diberikan siswa dan guru penjaskes, keterlaksanaan permainan pramuka dalam bentuk pemanasan juga dinilai dalam produk pengembangan ini.

Hasil akhir yang diperoleh dari masing-masing instrumen yang dikembangkan dalam penelitian ini diperoleh nilai rata-rata 85,53 masuk ke dalam kategori BAIK, sehingga produk pengembangan model permainan pramukayang lakukan peneliti dinyatakan layak untuk dapat diterapkan/digunakan dalam kegiatan pemanasan penjaskes di tingkat Sekolah Menengah Pertama (SMP).

\section{Kesimpulan}

Hasil yang didapat Berdasarkan hasil penelitian, makadapatdisimpulkansebagaiberikut: (1) Model pemanasan berbasis permainan pramuka pada siswa SMP menjadi sebuah gambaran dan pedoman untuk guru penjaskes dalam merancang dan memberikan bentuk emanasan yang variatif agar tidak monoton, (2) Model pemanasan berbasis permainan pramuka dapat meningkatkan kemampuan gerak siswa berdasarkan hasil penelitian yang dilaksanakan di 3 Sekolah Menegah Pertama yang ada di Kabupaten Landak, (3) Model pemanasan berbasis permainan pramuka yang dikembangkan dapat menjadi lebih efektif, hal tersebut didapatkan hasil yang diperoleh dari respon positif siswa sebesar 85,50 (Baik)dan dari guru sebesar 85,55 (Baik), rata-rata 85,53 (Baik).

\section{DAFTAR PUSTAKA}

Gall, M. D., Gall, J. P., \& Borg, W. R. (2007). Educational research: An introduction. Boston: Pearson/Allyn \&Bacon.

Arifin, Zenal. (2014). AktivitasPemanasan dan Pendinginan Pada Siswa Ekstrakurikuler Olahraga Di SMP Negeri Se-Kecamatan Semarang Timur Kota Semarang.

Jurnal. Seminar Nasional $\quad$ Evaluasi Pendidikan. Universitas Negeri Semarang

Burke,Edmund R. (2001). Latihan Kebugaran Di Rumah. Jakarta: PT RajaGrafindo Persada.

Hidayatullah, Furqoon. (2008). Mendidik Anak Dengan Bermain. Surakarta: LPP UNS dan UNS Press.

Husdarta,H.J.S. (2011). Manajemen Pendidikan Jasmani. Bandung: Alfabeta. 
Maryanti. (2014).Pelaksanaan Permainan Tradisional Dalam mendukung Perkembangan Prilaku Sosial Anak Usia Dini DiKelompok Bermain $\quad$ (KB) Alam Uswatun Khasanah, Kronggahan,Gamping, Sleman. Skripsi.

Universitas Negeri Yogyakarta. Sukardi.(2012). Permainan Pramuka di Lapangan.Gerakan pramuka Kwartir Daerah 11 Jawa Tengah:Saka Production

Selfianto, Dian, Agung.(2013). Pengembangan Macam-macam Pemanasan Melalui Permainan Air untuk Pembelajaran Renang Kelas X Di SMK Negeri 11 Kota Malang.Skripsi.Universitas Negeri Malang.

Sugiono. (2015). Metode Penelitian Pendidikan Pendekatan Kuantitatif Kualitatif, dan R\&D. Bandung: Alfabeta. 